\title{
A Review on the Development of Spaceborne Membrane Antennas
}

\author{
Ming-Jian Li (D, Meng Li, Yu-Fei Liu, Xin-Yu Geng, and Yuan-Yuan Li \\ Qian Xuesen Laboratory of Space Technology, China Academy of Space Technology, Beijing 100094, China \\ Correspondence should be addressed to Meng Li; limeng@qxslab.cn
}

Received 10 August 2021; Accepted 21 February 2022; Published 7 March 2022

Copyright (c) 2022 Ming-Jian Li et al. Exclusive Licensee Beijing Institute of Technology Press. Distributed under a Creative Commons Attribution License (CC BY 4.0).

\begin{abstract}
The membrane antenna technology is a very promising approach to obtain large aperture with light weight and low stowed volume. In the past decades, extensive studies have been carried out on active and passive membrane antennas. However, the practical spaceborne applications are rare due to many challenges, e.g., the surface accuracy maintenance, the on-orbit reliability, and the environmental compatibility. This paper summarizes the history and state-of-art progresses on spaceborne membrane antennas. Curved surface reflectors, conformal active membrane antennas, planar array membrane antennas, and planar reflectarray membrane antennas have been introduced, respectively. Radiofrequency design, deploying mechanism, material, experiment, application, and analysis method have been presented. By concluding the advantages and challenges of the current membrane antennas, this paper is aimed at providing a perspective of the existing problems and future trend of spaceborne membrane antennas.
\end{abstract}

\section{Introduction}

Spaceborne antennas are widely used in telecommunication, navigation, remote sensing, deep space exploration, military, and other fields [1], and they are developed towards high gain, high accuracy, lightweight, smart, and reconfigurable features. Despite the demands of miniaturization for many radiofrequency equipment, spaceborne antennas are often expected to have larger aperture. This is to achieve higher sensitivity and smaller terminals on earth. Besides, there are emerging interests in low-frequency applications, such as search and rescue at VHF and UHF, biomass synthetic aperture radar (SAR) at VHF, and other military programs. These trends call for spaceborne antennas with even larger physical size, e.g., several hundreds of square meters or larger.

Membrane antenna is a very promising approach to obtain large aperture, since membranes can be designed to have high areal compaction ratio. Compared with traditional rigid or umbrella type antennas, membrane antennas usually have lighter weight and smaller stowed volume. Compared with mesh antennas, membrane antennas can be designed to have less parts and higher reliability. In the past decades, extensive investigations on membrane antennas have been carried out in the United States [2, 3], Europe $[4,5]$, China
[6, 7], Japan [8-10], etc. However, in-orbit applications of membrane antennas are still rare, since many challenges exist in the membrane antenna study, among which the most important one is how to maintain high shape accuracy for a very thin membrane.

Membrane antennas can be divided into two categories: curved surface membrane antennas and planar membrane antennas. The curved surface ones are mostly parabolic, cylindrical, or spherical reflectors. Also, there are some studies on conformal active antennas with curved surface. The planar membrane antennas, on the other hand, include active array antennas and passive reflectarray antennas. Early explorations are mostly made on curved surface membrane reflectors. One successful on-orbit application is the IN-STEP (In-Space Technology Experiments Program) project [11-15] in 1996. Recently, planar membrane antennas have been developed very quickly, and one successful example is the R3D2 (Radiofrequency Risk Reduction Deployment Demonstration) satellite [16] launched in 2019.

Reviews on membrane antennas and their deploying structures/mechanisms can be found in the literature [2, 17-20]. Liu et al. [6] compared different types of membrane reflectors, including inflation [21], elastic rib driven [22, 23], 
shape memory polymer-inflation [24, 25], and electrostatic forming $[26,27]$. In recent years, the planar membrane antennas, especially the reflectarray antennas, have become increasingly attractive, but have not yet been discussed much in previous reviews. Therefore, this paper is aimed at presenting a review on the state-of-art membrane antennas, including the curved surface reflectors, the conformal membrane antennas, the planar array, and reflectarray antennas. History, cut-edge techniques, merits, and challenges will be introduced to present the development and prospect of spaceborne membrane antennas.

\section{Curved Surface Membrane Antennas}

2.1. Deployable Reflectors. Early studies of spaceborne membrane antennas were usually on inflatable reflectors. The first successful on-orbit application is the IN-STEP project (In-Space Technology Experiments Program) [11-15] in 1996. A 14-meter inflatable parabolic membrane reflector (Figure 1(a)) was deployed on orbit, and although the deploying sequence did not realize as planned because of underestimation of residual gas and strain energy, the reflector completed its deployment eventually. The objective of the experiment was mainly to validate the deploying mechanism and to measure the surface accuracy and structural damping. RF performance of this antenna is not available, but the authors mentioned the potential applications which include mobile communication, radiometry, microwave sensing, very long baseline interferometry, and space-based radar, ranging from 0.3 to $90 \mathrm{GHz}$.

The European Space Agency (ESA) and the Contraves Space Division [28] studied inflatable-rigidizable antennas (Figure 1(c)) from the 1980s. The reflectors with diameters from $3.5 \mathrm{~m}$ to $12 \mathrm{~m}$ were made of Kevlar fibers impregnated with polymer resins and would rigidize under solar radiation. The electromagnetic performances were tested for a $6 \mathrm{~m}$ reflector [29], which is a scale model $(1: 3)$ of the very long baseline interferometry satellite Quasat. Results suggested the antenna has $37.74 \mathrm{dBi}$ gain and $72.4 \%$ efficiency at $1.6 \mathrm{GHz}, 47.41 \mathrm{dBi}$ gain and $71.7 \%$ efficiency at $5.0 \mathrm{GHz}$, and $60.21 \mathrm{dBi}$ gain and $43.1 \%$ efficiency at $22 \mathrm{GHz}$. The surface errors were below $1 \mathrm{~mm}$ and would bring at most a gain degradation of $2.3 \mathrm{~dB}$. Other studies on inflatable reflectors can be found in the following years, such as a $3.2 \mathrm{~m}$ inflatable reflector [30], the $35 \mathrm{~m}$ inflatable reflector for the NEXRAD (Next Generation Weather Radar) project [31], and an inflatable parabolic reflector for CubeSats [32]. Wang et al. from HIT (Harbin Institute of Technology) [33] reported a $3 \mathrm{~m}$ lattice reinforced inflatable reflector (Figure 1(b)) in 2020. The membrane reflector consists of an inflatable chamber and a lattice reinforced structure made of shape memory polymer, while on orbit, it will be deployed by heating and inflating. After rigidization, the lattice structure can provide sufficient stiffness and the front membrane is no longer needed. The stiffness can be improved by over $50 \%$ compared with inflatable antenna.

The main problem of inflatable antennas is the shape and surface accuracy. The inflated gas will leak slowly, and potential micrometeoroid impacts will certainly accelerate this process. Although the rigidization technique and reinforced ribs can overcome this problem, a gas storage and pressurization system cannot be omitted. These factors will increase the weight and risk. Moreover, it is obviously more difficult to accurately maintain a curved surface than a planar configuration.

Using motor driven or strain energy driven truss is another way to deploy membrane reflectors. Elastic ribs can be used to deploy the parabolic membrane like an umbrella [34]. An elastic rib driven $1.5 \mathrm{~m}$ membrane reflector has been reported to have a surface accuracy of r.m.s. $2 \mathrm{~mm}$ [35]. Shape memory polymer (SMP) [24] can also be used as supporting structures of the reflector or to provide deploying force. TUM (Technical University of Munich) developed an umbrella-like antenna [36,37], which is deployed by springs controlled by one motor. A special material CFRS (carbon fibers which reinforce a silicone elastomer) was used, and it is stiffer than metal meshes and softer than solid panels and has been called shell-membrane. Experiments presented $0.2 \mathrm{~mm}$ r.m.s. error of this kind of reflector. RF tests from $8 \mathrm{GHz}$ to $10 \mathrm{GHz}$ suggested the reflection loss is less than $0.1 \mathrm{~dB}$.

From the 1980s, NASA began to study the electrostatic membrane reflectors, which use an electrode to create Coulomb's force, and attract the membrane to form a desirable curved surface [38]. Over the decades, many investigations have been carried out on electrostatic forming membrane reflectors, such as a $5 \mathrm{~m}$ antenna by SRS and Northrop Grumman [39] and the $0.5 \mathrm{~m}, 2 \mathrm{~m}$, and $5 \mathrm{~m}$ antennas by Xidian University (Figure 1(d)) [26].

2.2. Conformal Active Membrane Antennas. Membrane antennas with curved surfaces are mostly passive reflectors; however, several active membrane antennas with curved surfaces can be found. They are mainly used as conformal antennas on stratospheric airships, which are considered as promising alternatives of satellites in the future.

The Integrated Sensor Is Structure project [40] by DARPA (Defense Advanced Research Projects Agency) is aimed at flying a stratospheric airship at altitudes above $20,000 \mathrm{~m}$, which carries an integrated radar sensor for battlefield surveillance, tracking, and fire-control. The unmanned airship is designed to be a persistent, maintenance free satellite-like system, which never lands once aloft, and will work for over 10 years. The radar system adopts UHF and $\mathrm{X}$-band dual-frequency membrane phased-array antennas with a conformal design. The antenna has a low areal density $\left(<2 \mathrm{~kg} / \mathrm{m}^{2}\right)$ and is mounted on the surface of a cylindrical helium balloon, which is at overpressure than the airship to create a stable configuration. The antenna of the objective system has a diameter of $50.5 \mathrm{~m}$ and a height of $36 \mathrm{~m}$, with over tens of millions of elements, and the demonstration system is smaller. The cylindrical antenna can commutate the selection of subarrays to match the beam azimuth and to track all air, ground, and sea targets in $360^{\circ}$. Since tremendous amount of T/R modules are needed, a $5 \mathrm{~mm} \times 6 \mathrm{~mm}$ SiGe IC chip with a mass of less than $60 \mathrm{mg}$ is designed for the X-band module, and the long-term goal is to develop a sub- $\$ 10$ cost element. 


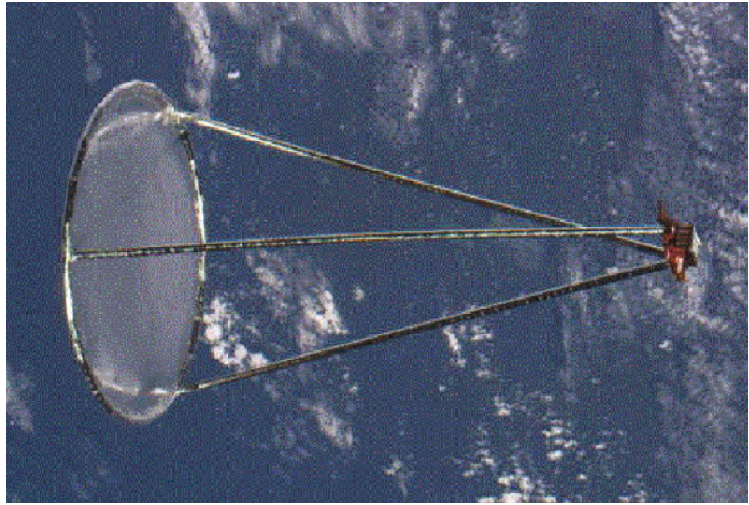

(a)

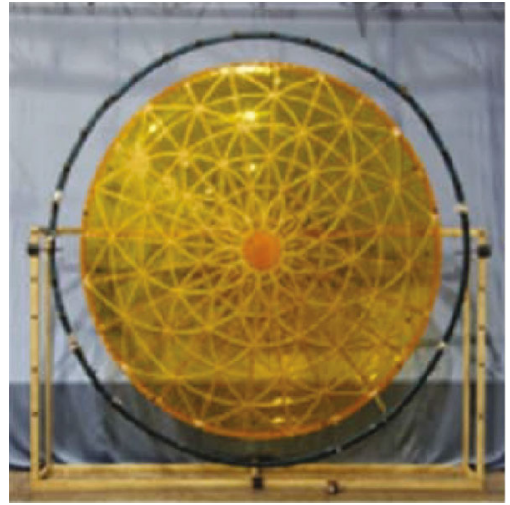

(b)

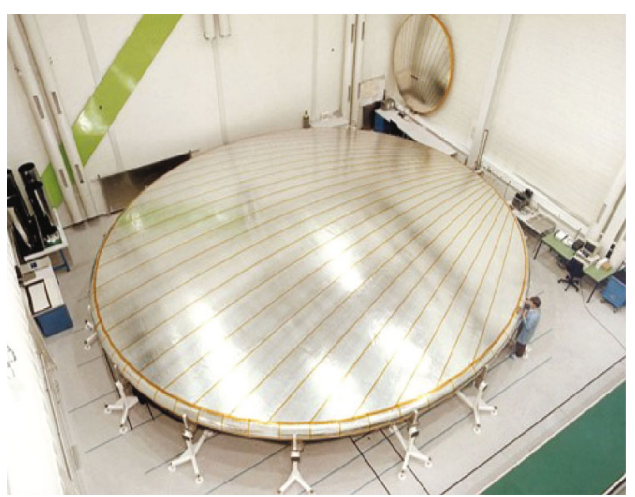

(c)

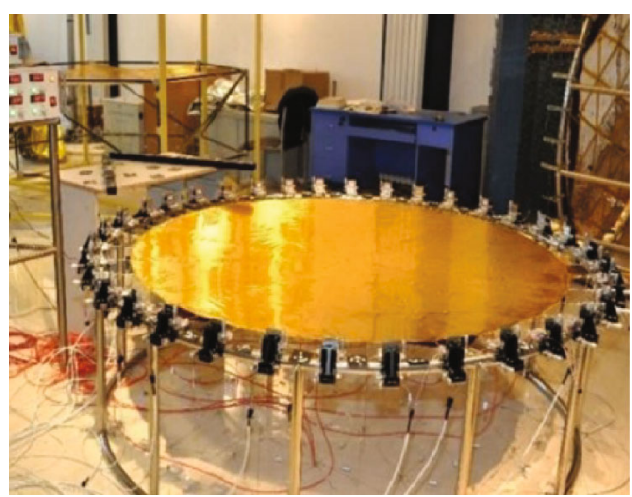

(d)

Figure 1: The curved surface deployable membrane reflectors. (a) The inflatable antenna experiment in 1996, first of its kind on-orbit. Image credit: NASA. (b) The SMP lattice reinforced inflatable reflector. Image credit: HIT [33]. (c) The $10 \mathrm{~m}$ inflatable membrane antenna. Image credit: ESA. (d) The electrostatic forming membrane reflector. Image credit: Xidian University.

The East China Research Institute of Electronic Engineering [41] presented a conformal membrane antenna on airships. The membrane patch antenna array with inflatable cavity is mounted on the surface of the airship and has a density of $0.6 \mathrm{~kg} / \mathrm{m}^{2}$. The size of the P-band phased array is about $2.96 \mathrm{~m} \times 7.92 \mathrm{~m}$. Tests suggested the antenna has $40 \%$ band width at the center frequency of $375 \mathrm{MHz}$, and the gain is about $10 \sim 12 \mathrm{~dB}$. The $8 \times 24$ conformal array can scan $30^{\circ}$ in the elevation plane and $45^{\circ}$ in the Azimuth plane.

Other types of conformal antenna can be found, which use membranes to deploy. Tokyo Institute of Technology presented a $3 \mathrm{U}$ CubeSat OrigamiSat-1 [42], with a $1 \mathrm{~m} \times 1$ $\mathrm{m}$ multifunctional deployable membrane, which integrates film solar cells and shape memory alloy dipole antennas. The antennas were connected to the UHF transmitter and VHF receiver. The CubeSat was launched in 2019 but then lost communication after six days.

\section{Planar Membrane Antennas}

3.1. Membrane Array Antennas. With the rapid development of phased-array antennas, the spaceborne platform calls for electronically steerable, large aperture, and lightweight antennas. Traditional phased-array antenna usually has a mass density of $8 \sim 15 \mathrm{~kg} / \mathrm{m}^{2}$ including antenna array, electronics, and mechanical structures. This cannot meet the requirements of future large aperture SAR (synthetic aperture radar). To achieve large aperture (several hundreds of square meters) with a small stowed volume, deployable membrane active array antennas have been developed.

In 1990s, JPL developed the first inflatable membrane array antenna. ILC Dover Inc. and L'Garde Corp constructed the L-band $1 / 3$ size functional model $(3.3 \mathrm{~m} \times 1 \mathrm{~m}$ ). The antenna consists of a rectangular inflated-tube frame and three-layer membranes with microstrip patch elements and circuits. The membrane is made of $50 \mu \mathrm{m}$ Kapton with $5 \mu \mathrm{m}$ copper etchings. The top layer has $6 \times 16$ microstrip patches and power dividing lines to provide horizontally polarized field; the middle layer is the ground plane with slots; the bottom layer has microstrip lines to provide a vertically polarized field. The antenna in average has a density of $1.7 \mathrm{~kg} / \mathrm{m}^{2}$ and has a $25.2 \mathrm{~dB}$ peak gain at $1.25 \mathrm{GHz}$ and a $52 \%$ aperture efficiency. CSA (Canadian Space Agency) [43-46] designed a membrane antenna, which can be used for sea-surface height altimeters and C-band synthetic aperture radars in low-Earth or planetary orbit. A $1.6 \mathrm{~m} \times 3 \mathrm{~m}$ model tensioned by catenary system was presented. Dynamic simulation and tension optimization have been carried out on the membrane antenna. DLR (German 
Aerospace Center) [47-49] designed a $12 \mathrm{~m} \times 3 \mathrm{~m}$ SAR membrane antenna supported by X-shape deployable CFRP (Carbon Fiber Reinforced Plastics) booms.

To achieve more flexible and lightweight active membrane antennas, new architectures and membrane-compatible transmit/receive (T/R) modules are needed. JPL developed an L-band membrane active phased array $[50,51]$ in 2011. The $2.3 \mathrm{~m} \times 2.6 \mathrm{~m}$ antenna has $16 \times 16$ elements and use very light $\mathrm{T} / \mathrm{R}$ modules for electronic beam steering. The top layer integrates $\mathrm{T} / \mathrm{R}$ electronics, the RF and $\mathrm{DC}$ distribution networks, and the ground plane. The bottom layer has bare dielectric on one side and radiating patches on the other side. The RF characteristics at $1.26 \mathrm{GHz}$ were tested, and good results have been achieved up to $30^{\circ}$ scan angle.

East China Research Institute of Electronic Engineering (ECRIEE) [7] presented a P-band dual circular polarization membrane antenna. The antenna consists of three layers with up and down radiating patches and ground plane. The $4.8 \mathrm{~m} \times 21.6 \mathrm{~m}$ antenna has $12 \times 36$ elements, which forms a transceiver subarray and two receiver subarrays. Tests suggested $27 \%$ bandwidth of the antenna, and good results were achieved up to $15^{\circ}$ scan angle. Aerospace System Engineering Shanghai [52] presented a $5 \mathrm{~m} \times 20 \mathrm{~m}$ membrane antenna in 2018. The antenna array has five layers: two layers with patches, a gap layer, a feed layer, and a reflection layer. Test results suggested the required $\pm 10 \mathrm{~mm}$ flatness has been met. The RF performance of this antenna is unavailable in the literature.

The planar membrane array antenna technology is developing towards large aperture, steerable, and lightweight, with miniaturized and membrane-compatible T/R modules.

3.2. Membrane Reflectarray Antennas. A reflectarray antenna uses a spatially illuminated feed and a planar reflector instead of a parabolic reflector in traditional antennas. By printing metal patches with different phase shifting characteristics on the substrate, the planar reflector can focus electromagnetic beam like a parabolic surface. On the one hand, compared with active array antennas, reflectarray antennas eliminate complex dividers, feed network, and phase shifters; thus, these can be simple and have light weight. On the other hand, compared with traditional reflector antennas, their design freedom is greatly improved through patch design, multilayer design, and other techniques, which can be helpful for low sidelobe and other technical requirements. Reflectarray antennas combine the advantages of reflectors and array antennas and have a very promising prospect.

For spaceborne uses, reflectarray patches can be conveniently printed on a planar membrane, and there is no need to maintain a complicated curved surface. In this way, the membrane can be designed to be folded in a very small stowed volume. Also, the deployable frames can be designed to have larger compaction ratio than parabolic antennas.

The concept of reflectarray antennas was introduced at 1963 by Berry et al. [53], but it has not been applied in space until very recently. The early reflectarray antenna consists of a feed and a short-circuited metal waveguide array. By adjusting the length of the waveguide, impedance and phase can be tuned. The early reflectarray is large and heavy and did not draw much attention in a long time. Phelan [54] introduced a four-arm spiral phase reflectarray concept in 1977 and used diodes to adjust phases. Malagisi [55] used circular patches with diodes to achieve beam steering abilities. In the 1980s and 1990s, with the rapid development of microstrip techniques, the reflectarray antennas became lightweight and had extensive applications. Many types of reflectarray antennas appeared, such as foldable reflectarray [56], full metal reflectarray $[57,58]$, inflatable reflectarray [59], beam forming reflectarray [60, 61], multifrequency reflectarray achieved by multilayer frequency selective structure designs [62-64], multifrequency reflectarray achieved by patch designs [65, 66], and multibeam reflectarray [67]. Microstrip reflectarray antennas can be designed to be flexible and suitable for mass production. Meanwhile, the costs can be effectively reduced by printing or etching microstrip elements on substrates. One important drawback of reflectarray antennas is that the bandwidth is narrow (usually $3 \%$ to $5 \%$ ). However, in recent years, many new techniques have emerged to solve this problem, such as multilayer designs [68], phase delay stub designs, [69], broadband patch designs [70], dual-frequency, or multifrequency combinations [71]. The bandwidth has been improved to over $10 \%$, even $30 \%$.

The first successful on-orbit reflectarray antenna is the antenna of the ISARA (Integrated Solar Array and Reflectarray Antenna) CubeSat $[72,73]$ by JPL in 2017 . The antenna is integrated with the solar panels and consists of three $33.9 \mathrm{~cm} \times 8.26 \mathrm{~cm}$ panels. The Ka-band reflectarray provides $33.5 \mathrm{dBi}$ gain and $\sim 24 \mathrm{~W}$ power within a mass of $0.5 \mathrm{~kg}$. It uses spring-loaded hinges to fold the panels and is stowed in a volume of $3 \mathrm{U}\left(10 \times 10 \times 33.5 \mathrm{~cm}^{3}\right)$. The second reflectarray ever flown in space is the antenna of the MarCO (Mars Cube One) mission [74] in 2018. The twin CubeSats were deployed to provide a data relay for the InSight spacecraft from a Mars distance of 160 million kilometers. Each antenna works with $29 \mathrm{dBi}$ at $8.4 \mathrm{GHz}$ and has an aperture of $59.7 \mathrm{~cm} \times 33.5 \mathrm{~cm}$, which is formed by three foldable panels. Other foldable reflectarray designs can be also be found, such as the dual polarized Ku-band antenna [75] for radar altimeter by JPL, which consists of five panels, and has a $2.16 \mathrm{~m} \times 0.35 \mathrm{~m}$ aperture. RF tests suggested $37 \mathrm{~dB}$ H-pol gain, and the efficiency is $25 \%$. The SWOT (Surface Water Ocean Topography) project [76] also planned to use a $5 \mathrm{~m} \times 0.25 \mathrm{~m}$ aperture reflectarray. Chahat et al. designed a $98.6 \mathrm{~cm} \times 82.1 \mathrm{~cm}$ Cassegrain reflectarray antenna, which consists of 14 panels, works at Ka-band with $48 \mathrm{dBi}$ gain for atmospheric measurement $[77,78]$.

In order to get higher compaction ratio and lower areal density, membranes are considered to be used as substrates of the spaceborne reflectarray antennas. Early investigations of membrane reflectarray antennas can be found in the 1990s. Huang et al. from JPL $[79,80]$ developed a $1 \mathrm{~m} \mathrm{X-}$ band inflatable reflectarray antenna. The two-layer membranes were tensioned by an inflated torus tube, and the feed horn was supported by tripod struts. The tubes are made of Kevlar with urethane coating. The spacing between two layers was $1.3 \mathrm{~mm}$ and was separated by many small foam discs. The membrane was made of $0.05 \mathrm{~mm}$ Kapton, with 
$5 \mu \mathrm{m}$ copper coating. RF tests suggested the circularly polarized antenna has $33.7 \mathrm{~dB}$ gain at $8.3 \mathrm{GHz}$ and a $-1 \mathrm{~dB}$ bandwidth of $3 \%$. The sidelobe level is $-18 \mathrm{~dB}$, which is higher than the expected $-25 \mathrm{~dB}$. The $37 \%$ efficiency was also not as expected $(50 \%)$. This is due to the manufacturing and other errors. Another $3 \mathrm{~m}$ inflatable membrane reflectarray antenna [81] was also designed by JPL and ILC Dover Inc. The frame was a horse-shoe shaped inflatable tube and was connected to the membrane with 16 adjustable points. A single layer $0.13 \mathrm{~mm}$ thick polyimide membrane was used, with one side clad with etched copper and the other side unetched copper as ground plane. Also, inflatable-rigidizable frames were designed to support the membrane reflectarray. RF tests suggested a $50 \mathrm{dBi}$ gain at $32 \mathrm{GHz}$, with a $-3 \mathrm{~dB}$ bandwidth of $2 \%$. The measured efficiency is only $10 \%$ (far from expected $40 \%$ ), which was due to a design flaw. A Ka-band $3 \mathrm{~m}$ antenna was presented by JPL [82]. The rectangular frame can be rolled up and down as a movie screen, and the tubes were made of rigidizable aluminum reinforced spring-tape. Once the booms were inflated in space, they will soon rigidize and no longer need the inflation gas.

Since these approach needs a system for gas storage and inflation, which has no benefits for lightweight and reliability, new deploying mechanisms have been proposed. Northrop Grumman and MMA Design LLC [83] designed the DaHGR (Deployable High Gain Reflectarray) antenna. Four motors are used to drive the bistable composite tapes and to control the rate and sequencing of the deployment. The membrane is supported and tensioned by a spring driven octagonal pantograph assembly. Antennas from $0.8 \mathrm{~m}$ to $3.6 \mathrm{~m}$ were studied, and folding and deploying experiments presented $0.6 \mathrm{~mm}$ to $0.9 \mathrm{~mm}$ r.m.s. surface errors. MMA Design LLC later reported a $2.25 \mathrm{~m}$ demonstration design ( $45.4 \mathrm{dBi}$ gain and $68 \%$ aperture efficiency), a $5 \mathrm{~m}$ prototype design, and a $4.2 \mathrm{~m} \mathrm{RF}$ design [84]. Also, the deployment is conducted by 4 motors, tapes, and tensioning lanyards. The pantograph around the membrane provides support and tension. MMA Design LLC also designed a $1 \mathrm{~m}$ TDaHGR antenna for the MAXWELL (Multiple Access Xband Wave Experiment Located in LEO) project [85], which is a $6 \mathrm{U}$ CubeSat as a part of the Air Force Research Laboratory's University Nanosat Program 9.

Arya et al. [86] from JPL presented a LADeR (LargeArea Deployable Reflectarray) antenna. The X-band reflectarray has 4340 cross-dipole elements. It is deployed by four booms and a cleverly designed mechanism. The substrate is neither a membrane, nor a solid panel. It is a collapsible composite structure with substantial bending stiffness. The antenna consists of several strips, which is made of epoxy reinforced with woven quartz fabric, and is wrapped to four $\mathrm{S}$-shape springs in a star folding way. Polyimide films with copper etching are attached to the composite substrates as the microstrip layer and ground layer. The $1.5 \mathrm{~m} \times 1.5 \mathrm{~m}$ antenna has a real density of $779 \mathrm{~g} / \mathrm{m}^{2}$ and presents a r.m.s. surface error of $0.5 \mathrm{~mm}$ in experiments. RF tests suggested $39.6 \mathrm{dBi}$ gain at $8.4 \mathrm{GHz}$, and the peak gain dropped by $0.3 \mathrm{~dB}$ after stowed.

The Capella-1 (Denali) satellite $[87,88]$ used an X-band SAR origami-like antenna with $8 \mathrm{~m}^{2}$ area. The total mass of the satellite is below $40 \mathrm{~kg}$ and was launched in 2018. It was the 1st satellite (for technology demonstration only) in a 30-satellite constellation designed by Capella Space. The design information is very limited in public literature, but it looks like a passive or active membrane antenna. However, Capella Space abandoned this design and used mesh antennas for Capella-2 (Sequoia) and the following satellites, which actually started to provide SAR imagery.

The first successful on-orbit membrane reflectarray is the antenna of the R3D2 (Radiofrequency Risk Reduction Deployment Demonstration) satellite by DARPA in 2019. The antenna designed by MMA Design LLC has a 2.25meter aperture and was deployed by motors and pantograph. This mission successfully demonstrated and verified the feasibility of membrane reflectarray antennas for spaceborne applications. The antenna works at UHF to Kaband; however, detailed RF performance is unavailable.

\section{Analysis, Prediction, and Maintenance of Accuracy}

Shape and surface accuracy is the most challenging problem in membrane antenna studies. Except for antenna uses, large deployable membrane structures can also be found in other aerospace areas, such as solar sails or drag deorbiting devices. However, none of these membrane structures require higher surface accuracy than membrane antennas, due to the direct relation between surface distortion and electromagnetic performance. Therefore, very careful investigations on the accuracy of membrane antennas are definitely necessary.

4.1. Mechanics of Wrinkles and Creases. The wrinkling phenomenon is caused by instability of thin membranes and is a typical failure in spaceborne membrane structures [89]. Wrinkles will lead to large surface distortion and deterioration of the antennas' electromagnetic performance. Theoretical and numerical studies on wrinkles are mainly based on the following two approaches:

4.1.1. Tension-Field Theory. This theory was initially studied by Wagner et al. [90]. It neglects the bending stiffness of membranes and assumes wrinkles occur in compressive area. Based on the tension-field theory, several approaches appeared including the modified constitutive matrix approaches [91-95] and the modified deformation tensor approaches $[96,97]$. These models have been applied in finite element algorithms $[98,99]$ and can predict in-plane wrinkling regions. However, the tension-field theory cannot obtain out-of-plane details of wrinkles and their evolutionary features; therefore, it is usually not suitable for accurate membrane deformation calculation in spaceborne antenna analysis.

4.1.2. Shell Buckling Theory. This theory assumes the membrane to be a thin shell with small bending stiffness, and instability will occur when compressive stress reaches the limit. The amplitude and wavelength of wrinkles can then be obtained by buckling analysis of the membrane [100-102]. 
In numerical applications, implicit algorithms $[103,104]$ and explicit schemes $[105,106]$ are used to achieve the out-ofplane details of wrinkles. Challenges exist in this method, such as its sensitivity to spatial discretization and difficulties in convergence, but it is still a very important approach to predict the mechanical behaviors of spaceborne membranes.

Creases are irrecoverable plastic deformation of the membranes, which will greatly affect the mechanical performance. Most of the studies on creases are based on the beam model. Early in 1966, MacNeal and Robbins [107] introduced an elastic-plastic beam model to analyze the deployment of a creased membrane. With the increasing deploying force, deformation will transfer from elastic to plastic region. Murphey [108] developed array beam models with triangular/rectangular patterns and sine/linear shapes, to study the random creases on deployable surfaces. Other investigations can be found on the deformation of stretching membranes with creases using the beam model [109-112], large deformation, crease rotational stiffness, and hinged beam connection model.

4.2. Structural Dynamics and Multiphysics Analysis. Due to the inherently nonlinearity of thin film structures, there are challenges in both theoretical and numerical approaches in structural dynamic analysis. Numerical nonlinear dynamic and stability analysis on large complex flexible membranes can be found $[46,113,114]$, for deployed membrane structures, while to simulate the deploying process, a rigidflexible coupling model considering hinge contact is needed. Moreover, for inflation deployment, a fluid-structural interaction algorithm based on arbitrary Lagrangian-Eulerian (ALE) method or particle method is necessary. The deploying analysis can be found in $[115,116]$.

The electromagnetic performance of membrane antennas is influenced by the on-orbit environment, which is a light-electromagnetic-thermal-structural coupling fields. Multiphysics analysis of antennas is mostly carried out by numerical methods [117-121] and usually focuses on the influence caused by structural deformation on the radiation pattern. Zhang et al. [122] studied the coupling effect between electromagnetic and structural field for a $14 \mathrm{~m}$ parabolic membrane antenna. Lu et al. [123] numerically studied a planar phased-array antenna in space thermal environment. Other researches include multiphysics coupling effect of planar active phased-array antennas [124, $125]$ and the structure-electronic synthesis design [126].

4.3. Experiments, Measurement, and Controlling Methods. At present, the main measurement methods for aerospace flexible structures are the digital photogrammetry method [127-129] and the laser scanning method [130]. Both static shape and vibration process can be measured. The photogrammetry tests on inflatable antenna in NASA Langley Research Center were reviewed [131].

For inflatable and mechanical driven membrane antennas, it is not easy to actively control the shape and surface accuracy of the reflector, once deployed on-orbit. Passive vibration control method usually uses dampers and cables. The electrostatic membrane reflectors mentioned above are a feasible real-time active control method. Other active control methods include boundary or cable controls $[132,133]$. Fang et al. [134] from JPL (Jet Propulsion Laboratory) presented a piezoelectric membrane control method. PVDF (polyvinylidene fluoride) membrane actuators were attached on the membrane reflector and provide driven force to control the shape of antenna. Both the electrostatic forming method and the piezoelectric actuators need very high voltage $(>1 \mathrm{kV})$, which greatly limit the their practical spaceborne applications.

4.4. Materials and Environmental Compatibility. Polyimide is the most commonly used candidate for spaceborne membrane antennas, due to its good mechanical properties, thermal stability, and antiradiation ability. Gouzman et al. [135] reviewed the advances of polyimide materials for space applications. During service in space, membranes are exposed to ultrahigh vacuum, ultraviolet radiation, ionizing radiation, and potential impacts from micrometeoroids and space debris [136]. At LEO (low Earth orbit), atomic oxygen can cause significant deterioration of polymers. Studies on mechanical properties degradation of polyimide membranes irradiated by atomic oxygen have been carried out [137, 138]. Other environmental effects include electrostatic charge and discharge, thermal cycles (usually from -100 to $100^{\circ} \mathrm{C}$ ), and collision of space debris or meteoroids with ultrahigh velocity of $\sim 10 \mathrm{~km} / \mathrm{s}$. A typical survivability improvement method for polyimide membrane is to add various protective coatings. For instance, $\mathrm{SiO}_{2}$ coating can be used to prevent atomic oxygen, and indium tin oxide (ITO) can be used for electrostatic discharge protection. Other coatings such as $\mathrm{TiO}_{2}, \mathrm{SnO}_{2}, \mathrm{Al}_{2} \mathrm{O}_{3}, \mathrm{NH}_{3}$, and $\mathrm{H}_{2} \mathrm{O}$ can be found [135, 139-141].

In addition to polyimide, other materials can be found for membrane antennas, such as the aforementioned epoxy reinforced with woven quartz fabric [86] and silicone elastomer reinforced with carbon fibers [37]. The materials for membrane antennas are developing towards better mechanical properties (high stiffness and low density) and better environmental compatibility (endurance of the various space hazards).

\section{Concluding Remarks}

Up until now, most of the membrane antennas are still in the stage of conceptual design and ground test. Compared to mature rigid surface antennas and metal mesh antennas, many techniques in membrane antennas still need to be validated and verified. However, as a new trend in spaceborne application, the membrane antenna technology, which can achieve large aperture with light weight and low storage volume, has a very promising future.

5.1. Challenges. The current difficulties in membrane antennas can be concluded as follows:

5.1.1. Theoretical Prediction and Design Method. Theoretical models, including analytical and numerical methods, are need to solve the nonlinear dynamic and multiphysics behaviors of membrane antennas. Considering wrinkles, 
creases, large deformation, and coupling effects of membrane antennas, a theoretical model which can accurately predict the on-orbit performance is definitely not easy to establish. Moreover, for very large aperture antennas, the ground test usually uses a smaller scaled model, and nondimensional and equivalent analysis is very challenging.

5.1.2. Monitoring, Maintaining, and Controlling of Shape and Surface Accuracy. Since a thin membrane has barely no bending stiffness, it will deform and vibrate under small disturbance and tends to vibrate for a long time due to a lack of damping. On-orbit real-time monitoring of the shape and surface accuracy is the first step to actively control the membrane. As mentioned above, the current control techniques are premature.

5.1.3. High Compaction Ratio Folding and Deploying Method. Folding and packing method with high compaction ratio is always desirable. The packing method should also cause less irrecoverable creases. Meanwhile, deploying mechanisms should be carefully designed, with less energy consumption, smooth and controllable process, and high reliability.

5.1.4. Lightweight and Reliable Substrates and Electronics. Materials for membrane should be light and environmental compatible, with sufficient stiffness and controllable thermal expansion. Also, materials and architectures of electronics should be optimized to achieve thin, light, and reliable modules.

5.2. Outlook. Based on current techniques, the future possible directions of spaceborne membrane antennas can be concluded as follows:

5.2.1. Towards Both Large-Scale and Small-Scale. Large aperture membrane antennas with high precision are in urgent need, in deep space exploration, high resolution earth observation, military, and other areas. Meanwhile, the development of small satellite and CubeSats also calls for flexible and multifunctional membrane antennas.

5.2.2. Towards Highly Predictable and Controllable. Theoretical tools to predict on-orbit behaviors of antennas are developing towards fast and accurate. The digital twin technology is among the new prediction methods. Also, membranes using new smart materials will achieve real-time and active control of the configuration and functions.

5.2.3. Towards Rigid-Flexible Combination. Current membrane antennas are coupled systems with flexible antennas and rigid frames. With the development mentioned above, structures with semirigidness, tunable stiffness, and other new features can be designed. Future membrane antennas may be flexible enough to be packed into a very small volume and achieve sufficient stiffness and surface accuracy after deployment.

\section{Data Availability}

The data of this study are available from the corresponding author upon request.

\section{Conflicts of Interest}

The authors declare no conflicts of interest to this work.

\section{Authors' Contributions}

Ming-Jian Li contributed to conceptualization, literature review, writing-original draft, and writing-review and editing. Meng Li, Yu-Fei Liu, Xin-Yu Geng, and YuanYuan Li contributed to conceptualization.

\section{Acknowledgments}

This work has been supported by the National Natural Science Foundation of China, under Grant No. 52105287, and the united research fund by Qian Xuesen Laboratory of Space Technology and China Spacesat Co., Ltd. (DFH).

\section{References}

[1] B. Duan, Y. Zhang, and J. Du, Large Deployable Satellite Antennas: Design Theory, Methods and Applications, Springer Nature, 2020.

[2] J. Pearson and R. Romanofsky, "Thin film antenna development and optimization," in 47th AIAA/ASME/ASCE/AHS/ ASC Structures, Structural Dynamics, and Materials Conference 14th AIAA/ASME/AHS Adaptive Structures Conference 7th, p. 2229, Newport, Rhode Island, USA, 2006.

[3] Y. Rahmat-Samii and R. Haupt, "Reflector antenna developments: a perspective on the past, present and future," IEEE Antennas and Propagation Magazine, vol. 57, no. 2, pp. 8595, 2015

[4] J.-C. Angevain, A. Ihle, G. Rodrigues, and J. Santiago-Prowald, "Large deployable spaceborne reflector antennas in Europe: progress status and perspectives," in 2019 13th European Conference on Antennas and Propagation (EuCAP), pp. 1-5, Krakow, Poland, 2019.

[5] J. Santiago-Prowald and H. Baier, "Advances in deployable structures and surfaces for large apertures in space," CEAS Space Journal, vol. 5, no. 3-4, pp. 89-115, 2013.

[6] Z.-Q. Liu, H. Qiu, X. Li, and S.-L. Yang, "Review of large spacecraft deployable membrane antenna structures," Chinese Journal of Mechanical Engineering, vol. 30, no. 6, pp. 1447-1459, 2017.

[7] Y. Zhang, "P band dual circular polarization membrane antenna array," in 2017 Sixth Asia-Pacific Conference on Antennas and Propagation (APCAP), pp. 1-3, Xi'an, China, 2017.

[8] Y. Shimoda, K. Watanabe, N. Sakamoto et al., "Development of stereo camera system for accurate observation of deployable membranes onboard CubeSat," 55th AIAA Aerospace Sciences Meeting, p. 0167, 2017.

[9] S. Nakasuka, R. Funase, K. Nakada, N. Kaya, and J. C. Mankins, "Large membrane "Furoshiki Satellite" applied to phased array antenna and its sounding rocket experiment," Acta Astronautica, vol. 58, no. 8, pp. 395-400, 2006. 
[10] H. Furuya and K. Miura, "Effects of tension and configuration in surface errors of membrane space antennas," International Journal of Space Structures, vol. 6, no. 3, pp. 219-226, 1991.

[11] R. Freeland and G. Bilyeu, "In-step inflatable antenna experiment," Acta Astronautica, vol. 30, pp. 29-40, 1993.

[12] R. Freeland, G. Bilyeu, and G. Veal, "Validation of a unique concept for a low-cost, lightweight space-deployable antenna structure," Acta Astronautica, vol. 35, no. 9-11, pp. 565-572, 1995.

[13] R. Freeland, G. D. Bilyeu, and G. R. Veal, "Development of flight hardware for a large, inflatable-deployable antenna experiment," Acta Astronautica, vol. 38, no. 4-8, pp. 251260, 1996.

[14] R. Freeland, G. Bilyeu, G. Veal, M. Steiner, and D. Carson, "Large inflatable deployable antenna flight experiment results," Acta Astronautica, vol. 41, no. 4-10, pp. 267-277, 1997.

[15] R. Freeland and G. Veal, "Significance of the inflatable antenna experiment technology," in 39th AIAA/ASME/ ASCE/AHS/ASC Structures, Structural Dynamics, and Materials Conference and Exhibit, p. 2104, Long Beach, California, USA, 1998.

[16] M. De Zwart and D. Stephens, "The space (innovation) race: the inevitable relationship between military technology and innovation," Melbourne Journal of International Law, vol. 20, p. 1, 2019.

[17] H. Huang, Z. Deng, and B. Li, "Mobile assemblies of large deployable mechanisms," Journal of Space Engineering, vol. 5, no. 1, pp. 1-14, 2012.

[18] S. Lu, D. Zlatanov, X. Ding, and R. Molfino, "A new family of deployable mechanisms based on the Hoekens linkage," Mechanism and Machine Theory, vol. 73, pp. 130-153, 2014.

[19] C. G. Cassapakis, A. W. Love, and A. L. Palisoc, "Inflatable space antennas-a brief overview," in 1998 IEEE Aerospace Conference Proceedings (Cat. No. 98TH8339), vol. 3, pp. 453-459, Snowmass, CO, USA, 1998.

[20] Y. Rahmat-Samii and A. Densmore, "A history of reflector antenna development: past, present and future," in 2009 SBMO/IEEE MTT-S International Microwave and Optoelectronics Conference (IMOC), pp. 17-23, Belem, Brazil, 2009.

[21] W. Stutzman, "Antennas and propagation in communication systems: past, present, and future," in 2016 IEEE International Symposium on Antennas and Propagation (APSURSI), pp. 683-684, Fajardo, PR, USA, 2016.

[22] F. Dewalque, J.-P. Collette, and O. Brüls, "Mechanical behaviour of tape springs used in the deployment of reflectors around a solar panel," Acta Astronautica, vol. 123, pp. 271282, 2016.

[23] Y. Miyazaki, M. Fukunaga, and D. Kousaka, "Membrane structure supported by selfdeployable truss for space applications," in 2018 AIAA Spacecraft Structures Conference, p. 1201, Kissimmee, Florida, USA, 2018.

[24] Y. Liu, H. Du, L. Liu, and J. Leng, "Shape memory polymers and their composites in aerospace applications: a review," Smart Materials and Structures, vol. 23, no. 2, article 023001, 2014.

[25] S. Jape, M. Garza, J. Ruff et al., "Self-foldable origami reflector antenna enabled by shape memory polymer actuation," Smart Materials and Structures, vol. 29, no. 11, article 115011, 2020.
[26] Y. Zhang, F. Gao, S. Zhang, and J. Hao, "Electrode grouping optimization of electrostatic forming membrane reflector antennas," Aerospace Science and Technology, vol. 41, pp. 158-166, 2015.

[27] C. Liu and Y. Shi, "Comprehensive structural analysis and optimization of the electrostatic forming membrane reflector deployable antenna," Aerospace Science and Technology, vol. 53, pp. 267-279, 2016.

[28] D. Cadogan and S. Scarborough, "Rigidizable materials for use in gossamer space inflatable structures," in 19th AIAA Applied Aerodynamics Conference, Anaheim, California, USA, 2001.

[29] K. van't Klooster, W. Rits, E. Pagana, P. Mantica, and M. Bernasconi, "An inflatable parabolic reflector antennaits realisation and electrical predictions," ESA Journal, vol. 14, no. 2, pp. 211-216, 1990.

[30] Y. Xu and F.-l. Guan, "Structure design and mechanical measurement of inflatable antenna," Acta Astronautica, vol. 76, pp. 13-25, 2012.

[31] M. J. Coleman, F. Baginski, and R. R. Romanofsky, "Effect of boundary support and reflector dimensions on inflatable parabolic antenna performance," Journal of Spacecraft and Rockets, vol. 49, no. 5, pp. 905-914, 2012.

[32] J. Lin, H. Fang, E. Im, and U. Quijano, "Concept study of a 35-m spherical reflector system for NEXRAD in space application," in 47th AIAA/ASME/ASCE/AHS/ASC Structures, Structural Dynamics, and Materials Conference 14th AIAA/ ASME/AHS Adaptive Structures Conference 7th, p. 1604, Newport, Rhode Island, USA, 2006.

[33] Q. Tao, C. Wang, K. Wang, and H. Tan, "Mixed triangle lattice reinforced membrane antenna reflector: design and analysis," AIAA Journal, vol. 58, no. 4, pp. 1897-1900, 2020.

[34] K. Seffen, Z. You, and S. Pellegrino, "Folding and deployment of curved tape springs," International Journal of Mechanical Sciences, vol. 42, no. 10, pp. 2055-2073, 2000.

[35] S. Pellegrino, "Deployable membrane reflectors," 2nd World Engineering Congress, vol. 22, p. 25, 2002.

[36] L. Datashvili, N. Nathrath, M. Lang et al., "New concepts and reflecting materials for space borne large deployable reflector antennas," 28th ESA Antenna Workshop on Space Antenna Systems and Technologies, 2005.

[37] L. Datashvili, H. Baier, E. Wehrle, T. Kuhn, and J. Hoffmann, "Large shell-membrane space reflectors," in 51st AIAA/ ASME/ASCE/AHS/ASC Structures, Structural Dynamics, and Materials Conference 18th AIAA/ASME/AHS Adaptive Structures Conference 12th, p. 2504, Orlando, Florida, USA, 2010.

[38] D. Mihora, Test Progress on the Electrostatic Membrane Reflector, 1981.

[39] S. Chodimella, J. Moore, J. Otto, and H. Fang, "Design evaluation of a large aperture deployable antenna," in 47th AIAA/ ASME/ASCE/AHS/ASC Structures, Structural Dynamics, and Materials Conference 14th AIAA/ASME/AHS Adaptive Structures Conference 7th, p. 1603, Newport, Rhode Island, USA, 2006.

[40] T. Clark and E. Jaska, "Million element ISIS array," in 2010 IEEE International Symposium on Phased Array Systems and Technology, pp. 29-36, Waltham, MA, USA, 2010.

[41] Y. Zhang and J. Chen, "Membrane patch anetnna array with inflatable cavity," in 2019 International Symposium on Antennas and Propagation (ISAP), pp. 1-3, Xi'an, China, 2019. 
[42] K. Ikeya, H. Sakamoto, H. Nakanishi et al., "Significance of $3 \mathrm{u}$ CubeSat OrigamiSat-1 for space demonstration of multifunctional deployable membrane," Acta Astronautica, vol. 173, pp. 363-377, 2020.

[43] G. Séguin, T. Pellerin, J. Colinas et al., "Membrane antenna for SAR satellite," in 2002 9th International Symposium on Antenna Technology and Applied Electromagnetics, pp. 1-4, St. Hubert, QC, Canada, 2002.

[44] J. Heald and X. X. Jiang, "Effects of low-earth orbit space environment on structural mechanics of a deployable membrane space antenna," in 48th AIAA/ASME/ASCE/AHS/ASC Structures, Structural Dynamics, and Materials Conference, p. 2181, Honolulu, Hawaii, USA, 2007.

[45] J. Heald, M.-J. Potvin, and X. X. Jiang, "Experimental investigations to support a multi-layer deployable membrane structure for space antenna," in 46th AIAA/ASME/ASCE/AHS/ ASC Structures, Structural Dynamics and Materials Conference, p. 2317, Austin, Texas, USA, 2005.

[46] Y. Shen, S. Montminy, W. Zheng, V. Tokateloff, M.-J. Potvin, and G. Akhras, "Large SAR membrane antenna deployable structure design and dynamic simulation," in 48th AIAA/ ASME/ASCE/AHS/ASC Structures, Structural Dynamics, and Materials Conference, p. 2333, Honolulu, Hawaii, USA, 2007.

[47] M. Straubel, Design and Sizing Method for Deployable Space Antennas, Ph.D. dissertation, Deutsches Zentrum für Luftund Raumfahrt eV, 2012.

[48] M. Leipold, H. Runge, and C. Sickinger, "Large SAR membrane antennas with lightweight deployable booms," in 28th ESA Antenna Workshop on Space Antenna Systems and Technologies, ESA/ESTEC. European Space and Technology Research Centre Noordwijk, pp. 1-8, The Netherlands, 2005.

[49] M.-J. Potvin, S. Montminy, S. Brunel et al., "Testing of a deployable SAR membrane antenna mechanical prototype," in 49th AIAA/ASME/ASCE/AHS/ASC Structures, Structural Dynamics, and Materials Conference, 16th AIAA/ASME/ AHS Adaptive Structures Conference, 10th AIAA NonDeterministic Approaches Conference, 9th AIAA Gossamer Spacecraft Forum, 4th AIAA Multidisciplinary Design Optimization Specialists Conference, p. 2208, Schaumburg, Illinois, USA, 2008.

[50] A. Moussessian, L. Del Castillo, V. Bach et al., Large Aperture, Scanning, L-Band Sar, 2011.

[51] A. Moussessian, L. Del Castillo, M. Zawadzki et al., "An electronically scanned large aperture membrane array," in NASA Space Technology Conference, vol. 6, Pasadena, California, USA, 2007.

[52] X. Chao, Y. Biao, and L. Yu, "High precision manufacturing technology for space-based membrane antennas," Manned Spaceflight, vol. 24, no. 1, pp. 79-83, 2018.

[53] D. Berry, R. Malech, and W. Kennedy, "The reflectarray antenna," IEEE Transactions on Antennas and Propagation, vol. 11, no. 6, pp. 645-651, 1963.

[54] H. R. Phelan, "Spiraphase reflectarray for multitarget radar," Microwave Journal, vol. 20, p. 67, 1977.

[55] C. Malagisi, "Microstrip disc element reflect array," EASCON'78; Electronics and Aerospace Systems Convention, pp. 186-192, 1978.

[56] D. Pilz and W. Menzel, "Folded reflectarray antenna," Electronics Letters, vol. 34, no. 9, pp. 832-833, 1998.
[57] Y. H. Cho, W. J. Byun, and M. S. Song, "High gain metal-only reflectarray antenna composed of multiple rectangular grooves," IEEE Transactions on Antennas and Propagation, vol. 59, no. 12, pp. 4559-4568, 2011.

[58] W. An, S. Xu, and F. Yang, "A metal-only reflectarray antenna using slot-type elements," IEEE Antennas and Wireless Propagation Letters, vol. 13, pp. 1553-1556, 2014.

[59] J. Huang and A. Feria, "Inflatable microstrip reflectarray antennas at X and Ka-band frequencies," in IEEE Antennas and Propagation Society International Symposium. 1999 Digest. Held in conjunction with: USNC/URSI National Radio Science Meeting (Cat. No. 99CH37010), vol. 3, pp. 1670-1673, Orlando, FL, USA, 1999.

[60] D. Pozar, S. Targonski, and R. Pokuls, "A shaped-beam microstrip patch reflectarray," IEEE Transactions on Antennas and Propagation, vol. 47, no. 7, pp. 1167-1173, 1999.

[61] J. A. Encinar, L. S. Datashvili, J. A. Zornoza et al., "Dualpolarization dual-coverage reflectarray for space applications," IEEE Transactions on Antennas and Propagation, vol. 54, no. 10, pp. 2827-2837, 2006.

[62] J. Encinar, "Design of a dual frequency reflectarray using microstrip stacked patches of variable size," Electronics Letters, vol. 32, no. 12, pp. 1049-1050, 1996.

[63] C. Han, C. Rodenbeck, J. Huang, and K. Chang, "A C/Ka dual frequency dual layer circularly polarized reflectarray antenna with microstrip ring elements," IEEE Transactions on Antennas and Propagation, vol. 52, no. 11, pp. 2871-2876, 2004.

[64] R. Deng, F. Yang, S. Xu, and M. Li, “An FSS-backed 20/30$\mathrm{GHz}$ dual-band circularly polarized reflectarray with suppressed mutual coupling and enhanced performance," IEEE Transactions on Antennas and Propagation, vol. 65, no. 2, pp. 926-931, 2017.

[65] F. Yang, Y. Kim, J. Huang, and A. Elsherbeni, “A single-layer tri-band reflectarray antenna design," in 2007 IEEE Antennas and Propagation Society International Symposium, pp. 53075310, Honolulu, HI, USA, 2007.

[66] M. Borgese, F. Costa, S. Genovesi, and A. Monorchio, "An iterative design procedure for multiband single-layer reflectarrays: design and experimental validation," IEEE Transactions on Antennas and Propagation, vol. 65, no. 9, pp. 4595-4606, 2017.

[67] P. Nayeri, F. Yang, and A. Z. Elsherbeni, "Design of singlefeed reflectarray antennas with asymmetric multiple beams using the particle swarm optimization method," IEEE Transactions on Antennas and Propagation, vol. 61, no. 9, pp. 4598-4605, 2013.

[68] J. A. Encinar and J. A. Zornoza, "Broadband design of threelayer printed reflectarrays," IEEE Transactions on Antennas and Propagation, vol. 51, no. 7, pp. 1662-1664, 2003.

[69] F. Xue, H.-J. Wang, M. Yi, G. Liu, and X.-c. Dong, "Design of a broadband single-layer linearly polarized reflectarray using four-arm spiral elements," IEEE Antennas and Wireless Propagation Letters, vol. 16, pp. 696-699, 2017.

[70] P.-Y. Qin, Y. J. Guo, and A. R. Weily, "Broadband reflectarray antenna using subwavelength elements based on double square meander-line rings," IEEE Transactions on Antennas and Propagation, vol. 64, no. 1, pp. 378-383, 2016.

[71] R. Deng, S. Xu, F. Yang, and M. Li, "A single-layer highefficiency wideband reflectarray using hybrid design approach," IEEE Antennas and Wireless Propagation Letters, vol. 16, pp. 884-887, 2017. 
[72] R. E. Hodges, M. J. Radway, A. Toorian, D. J. Hoppe, B. Shah, and A. E. Kalman, "ISARAintegrated solar array and reflectarray CubeSat deployable Ka-band antenna," in 2015 IEEE International Symposium on Antennas and Propagation \& USNC/URSI National Radio Science Meeting, pp. 21412142, Vancouver, BC, Canada, 2015.

[73] F. Davarian, A. Babuscia, J. Baker et al., "Improving small satellite communications in deep space-a review of the existing systems and technologies with recommendations for improvement. Part i: direct to earth links and SmallSat telecommunications equipment," IEEE Aerospace and Electronic Systems Magazine, vol. 35, no. 7, pp. 8-25, 2020.

[74] R. Hodges, N. Chahat, D. Hoppe, and J. Vacchione, "The mars cube one deployable high gain CubeSat antenna," IEEE Antennas and Propagation Magazine, vol. 59, no. 2, pp. 3949, 2017.

[75] R. E. Hodges and M. Zawadzki, "Design of a large dual polarized Ku band reflectarray for space borne radar altimeter," in IEEE Antennas and Propagation Society Symposium, vol. 4, pp. 4356-4359, Monterey, CA, USA, 2004.

[76] P. Vaze, S. Kaki, D. Limonadi, D. Esteban-Fernandez, and G. Zohar, "The surface water and ocean topography mission," in 2018 IEEE Aerospace Conference, pp. 1-9, Big Sky, Montana, USA, 2018.

[77] N. Chahat, G. Agnes, J. Sauder, and T. Cwik, "One meter deployable reflectarray antenna for earth science radars," in 2017 IEEE International Symposium on Antennas and Propagation \& USNC/URSI National Radio Science Meeting, pp. 245-246, San Diego, CA, USA, 2017.

[78] N. Chahat, E. Thiel, J. Sauder, M. Arya, and T. Cwik, "Deployable one-meter reflectarray for 6U-class CubeSats," in 2019 13th European Conference on Antennas and Propagation (EuCAP), pp. 1-4, Krakow, Poland, 2019.

[79] J. Huang and A. Feria, "A 1-m X-band inflatable reflectarray antenna," Microwave and Optical Technology Letters, vol. 20, no. 2, pp. 97-99, 1999.

[80] J. Huang, "The development of inflatable array antennas," IEEE Antennas and Propagation Magazine, vol. 43, no. 4, pp. 44-50, 2001.

[81] J. Lin, D. Cadogan, V. Feria, and J. Huang, "An inflatable microstrip reflectarray concept for Ka-band applications," in 41st Structures, Structural Dynamics, and Materials Conference and Exhibit, p. 1831, Atlanta, Georgia, USA, 2000.

[82] H. Fang, M. Lou, J. Huang, U. Quijiano, and L.-M. Hsia, "Thermal distortion analyses of a three-meter inflatable reflectarray antenna," in 44th AIAA/ASME/ASCE/AHS/ASC Structures, structural dynamics, and materials conference, p. 1650, Norfolk, Virginia, USA, 2003.

[83] P. K. Kelly, "A scalable deployable high gain antennaDaHGR," in 30th Annual AIAA/USU Conference on Small Satellites, Logan, Utah, USA, 2016.

[84] M. Cooley, B. Yon, D. Konapelsky et al., "RF design and development of a deployable membrane reflectarray antenna for space," in 2019 IEEE International Symposium on Phased Array System \& Technology (PAST), pp. 1-4, Waltham, MA, USA, 2019.

[85] Y. Khatri, A. P. Aboaf, D. Dowd, C. Flood, H. Dixon, and P. Axelrad, Csac Flight Experiment to Characterize on-Orbit Performance, 2020.
[86] M. Arya, J. F. Sauder, R. Hodges, and S. Pellegrino, "Largearea deployable reflectarray antenna for CubeSats," AIAA Scitech 2019 Forum, p. 2257, 2019.

[87] D. Werner, Capella unveils radar satellite designhttps:// spacenews.com/capella-whitneydesign.

[88] Capella, Capella space is the first U.S. company to launch and operate synthetic aperture radar (SAR) satelliteshttps://www. capellaspace.com.

[89] C. H. Jenkins, Recent Advances in Gossamer Spacecraft, American Institute of Aeronautics and Astronautics, 2006.

[90] H. Wagner, "Flat sheet metal girders with very thin metal web," Z. Flugtechn. Motorluftschiffahrt, vol. 20, pp. 200-314, 1929.

[91] M. Stein and J. M. Hedgepeth, Analysis of partly wrinkled membranes, National Aeronautics and Space Administration, 1961.

[92] R. K. Miller and J. M. Hedgepeth, "An algorithm for finite element analysis of partly wrinkled membranes," AIAA Journal, vol. 20, no. 12, pp. 1761-1763, 1982.

[93] E. Haseganu and D. Steigmann, "Analysis of partly wrinkled membranes by the method of dynamic relaxation," Computational Mechanics, vol. 14, no. 6, pp. 596-614, 1994.

[94] H. Ding and B. Yang, "The modeling and numerical analysis of wrinkled membranes," International Journal for Numerical Methods in Engineering, vol. 58, no. 12, pp. 1785-1801, 2003.

[95] A. Jarasjarungkiat, R. Wüchner, and K.-U. Bletzinger, “A wrinkling model based on material modification for isotropic and orthotropic membranes," Computer Methods in Applied Mechanics and Engineering, vol. 197, no. 6-8, pp. 773-788, 2008.

[96] D. Roddeman, J. Drukker, C. Oomens, and J. Janssen, "The wrinkling of thin membranes: part I-theory," Journal of Applied Mechanics, vol. 54, no. 4, pp. 884-887, 1987.

[97] M. Epstein and M. A. Forcinito, "Anisotropic membrane wrinkling: theory and analysis," International Journal of Solids and Structures, vol. 38, no. 30-31, pp. 5253-5272, 2001.

[98] N. Pimprikar, B. Banerjee, D. Roy, R. Vasu, and S. Reid, "New computational approaches for wrinkled and slack membranes," International Journal of Solids and Structures, vol. 47, no. 18-19, pp. 2476-2486, 2010.

[99] R. de Rooij and M. Abdalla, "A finite element interior-point implementation of tension field theory," Computers \& Structures, vol. 151, pp. 30-41, 2015.

[100] W. Wong and S. Pellegrino, "Wrinkled membranes ii: analytical models," Journal of Mechanics of Materials and Structures, vol. 1, no. 1, pp. 27-61, 2006.

[101] C. Wang, H. Tan, X. Du, and Z. Wan, "Wrinkling prediction of rectangular shell-membrane under transverse in-plane displacement," International Journal of Solids and Structures, vol. 44, no. 20, pp. 6507-6516, 2007.

[102] C. Wang, X. Du, H. Tan, and X. He, "A new computational method for wrinkling analysis of gossamer space structures," International Journal of Solids and Structures, vol. 46, no. 6, pp. 1516-1526, 2009.

[103] Y. Tomita and A. Shindo, "Onset and growth of wrinkles in thin square plates subjected to diagonal tension," International Journal of Mechanical Sciences, vol. 30, no. 12, pp. 921-931, 1988.

[104] W. Wong and S. Pellegrino, "Wrinkled membranes III: numerical simulations," Journal of Mechanics of Materials and Structures, vol. 1, no. 1, pp. 63-95, 2006. 
[105] M. Taylor, K. Bertoldi, and D. J. Steigmann, "Spatial resolution of wrinkle patterns in thin elastic sheets at finite strain," Journal of the Mechanics and Physics of Solids, vol. 62, pp. 163-180, 2014.

[106] T.-Y. Wu and E. C. Ting, "Large deflection analysis of 3D membrane structures by a 4 -node quadrilateral intrinsic element," Thin-Walled Structures, vol. 46, no. 3, pp. 261-275, 2008.

[107] R. MacNeal and W. Robbins, Tensile properties of a tape with a transverse crease, ASTRO Research Corporation, Santa Barbara, CA, 1967, Technical Report No. NAS7-426.

[108] T. W. Murphey, A Nonlinear Elastic Constitutive Model for Wrinkled Thin Films, University of Colorado at Boulder, 2000.

[109] K. Woo, K. Nandukar, and C. H. Jenkins, "Effective modulus of creased thin membranes," Journal of Spacecraft and Rockets, vol. 45, no. 1, pp. 19-26, 2008.

[110] A. Gough, N. Hossain, C. Jenkins, J. Blandino, and A. Hendricks, "Experimental and numerical study of creased membranes," in 46th AIAA/ASME/ASCE/AHS/ASC Structures, Structural Dynamics and Materials Conference, p. 1976, Austin, Texas, USA, 2005.

[111] N. Hossain, K. Woo, and C. Jenkins, "Nonlinear material response of systematically creased membranes," in 47th AIAA/ASME/ASCE/AHS/ASC Structures, Structural Dynamics, and Materials Conference 14th AIAA/ASME/AHS Adaptive Structures Conference 7th, p. 1801, Newport, Rhode Island, USA, 2006.

[112] Z. Xia, C. Wang, and H. Tan, "Quasi-static unfolding mechanics of a creased membrane based on a finite deformation crease-beam model," International Journal of Solids and Structures, vol. 207, pp. 104-112, 2020.

[113] Y. Shen, W. Zheng, and X. Wang, "Dynamic and vibration analysis of a SAR membrane antenna," ASME International Mechanical Engineering Congress and Exposition, vol. 42959, pp. 17-24, 2007.

[114] H. Fang, B. Yang, H. Ding, J. Hah, U. Quijano, and J. Huang, Dynamic Analysis of Large in-Space Deployable Membrane Antennas, 2006.

[115] J. Wang and A. Johnson, "Deployment simulation of ultralightweight inflatable structures," in 43rd AIAA/ASME/ ASCE/AHS/ASC Structures, Structural Dynamics, and Materials Conference, p. 1261, Denver, Colorado, USA, 2002.

[116] J. Wei, H. Tan, J. Yu, and X. Du, "Numerical simulations for gas-structure interaction in inflated deployment of folded membrane boom," Theoretical and Applied Mechanics Letters, vol. 2, no. 2, article 022004, 2012.

[117] C. Wang, B. Duan, F. Zhang, and M. Zhu, "Coupled structural-electromagnetic-thermal modelling and analysis of active phased array antennas," IET microwaves, antennas \& propagation, vol. 4, no. 2, pp. 247-257, 2010.

[118] L. Song, B. Duan, F. Zheng, and F. Zhang, "Performance of planar slotted waveguide arrays with surface distortion," IEEE Transactions on Antennas and Propagation, vol. 59, no. 9, pp. 3218-3223, 2011.

[119] P. Lian, B. Duan, W. Wang, C. Wang, S. Zhang, and B. Xiang, "A pattern approximation method for distorted reflector antennas using piecewise linear fitting of the exponential error term," IEEE Transactions on Antennas and Propagation, vol. 63, no. 10, pp. 4546-4551, 2015.
[120] B. Duan, H. Qiao, and L. Zeng, "The multi-field-coupled model and optimization of absorbing material's position and size of electronic equipments," Journal of Mechatronics and Applications, vol. 2010, 6 pages, 2010.

[121] B. Duan, Electromechanical Coupling Theory, Method and Application of Electronic Equipment, Science Press, Beijing, 2011.

[122] X. Zhang, S. Zhang, Z. Cheng et al., "Structuralelectromagnetic bidirectional coupling analysis of space large film reflector antennas," Acta Astronautica, vol. 139, pp. 502-511, 2017.

[123] G.-Y. Lu, J.-Y. Zhou, G.-P. Cai, G.-Q. Fang, L.-L. Lv, and F.J. Peng, "Studies of thermal deformation and shape control of a space planar phased array antenna," Aerospace Science and Technology, vol. 93, pp. 105311-105311, 2019.

[124] C. Wang, M. Kang, W. Wang, B. Duan, L. Lin, and L. Ping, "On the performance of array antennas with mechanical distortion errors considering element numbers," International Journal of Electronics, vol. 104, no. 3, pp. 462-484, 2017.

[125] L. Fan, L. L. Lv, F. J. Peng, and G. P. Cai, "Coupled structuralelectromagnetic modeling and analysis of active membrane phased array antenna," Advances in Space Research, vol. 66, no. 4, pp. 760-770, 2020.

[126] Y. Xu and F.-L. Guan, "Structure-electronic synthesis design of deployable truss antenna," Aerospace Science and Technology, vol. 26, no. 1, pp. 259-267, 2013.

[127] C. Fraser and D. Brown, "Industrial photogrammetry: new developments and recent applications," The Photogrammetric Record, vol. 12, no. 68, pp. 197-217, 1986.

[128] Y. Shen, G. Lin, C. Wang, and H. Tan, "Shape adjustment of flexible rib for large deployable reflector," AIAA Journal, vol. 57, no. 10, pp. 4569-4576, 2019.

[129] X. Luo, H. Tan, G. Lin, and Y. Lian, "Strain field measurements using digital photogrammetry for large inflatable structures," Experimental Techniques, vol. 41, no. 5, pp. 453-462, 2017.

[130] J. L. Gaspar, M. J. Solter, and R. S. Pappa, "Membrane vibration studies using a scanning laser vibrometer," in 20th International Modal Analysis Conference, NASA Technical Memorandum No. NASA/TM-2002-211427, 2001.

[131] R. S. Pappa, J. T. Black, J. R. Blandino, T. W. Jones, P. M. Danehy, and A. A. Dorrington, "Dot-projection photogrammetry and videogrammetry of gossamer space structures," Journal of Spacecraft and Rockets, vol. 40, no. 6, pp. 858$867,2003$.

[132] J. Lindler and E. Flint, "Boundary actuation shape control strategies for thin film single surface shells," in 45th AIAA/ ASME/ASCE/AHS/ASC Structures, Structural Dynamics \& Materials Conference, p. 1825, Palm Springs, California, USA, 2004.

[133] H. DeSmidt, K.-W. Wang, and H. Fang, "Optimized gore/ seam cable actuated shape control of gossamer membrane reflectors," Journal of Spacecraft and Rockets, vol. 44, no. 5, pp. 1122-1130, 2007.

[134] H. Fang, U. Quijano, V. Bach, J. Hill, and K.-W. Wang, "Experimental study of a membrane antenna surface adaptive control system," in 52nd AIAA/ASME/ASCE/AHS/ASC Structures, Structural Dynamics and Materials Conference 19th AIAA/ASME/AHS Adaptive Structures Conference 13t, p. 1828, Denver, Colorado, USA, 2011.

[135] I. Gouzman, E. Grossman, R. Verker, N. Atar, A. Bolker, and N. Eliaz, "Advances in polyimide-based materials for space 
applications," Advanced Materials, vol. 31, no. 18, article 1807738, 2019.

[136] P. Fortescue, G. Swinerd, and J. Stark, Spacecraft Systems Engineering, John Wiley \& Sons, 2011.

[137] H. Shimamura and I. Yamagata, "Degradation of mechanical properties of polyimide film exposed to space environment," Journal of Spacecraft and Rockets, vol. 46, no. 1, pp. 15-21, 2009.

[138] H. Shimamura and T. Nakamura, "Mechanical properties degradation of polyimide films irradiated by atomic oxygen," Polymer Degradation and Stability, vol. 94, no. 9, pp. 13891396, 2009.

[139] T. K. Minton, B. Wu, J. Zhang et al., "Protecting polymers in space with atomic layer deposition coatings," ACS Applied Materials \& Interfaces, vol. 2, no. 9, pp. 2515-2520, 2010.

[140] S. Duo, M. Li, M. Zhu, and Y. Zhou, "Polydimethylsiloxane/ silica hybrid coatings protecting Kapton from atomic oxygen attack," Materials Chemistry and Physics, vol. 112, no. 3, pp. 1093-1098, 2008.

[141] I. Gouzman, O. Girshevitz, E. Grossman, N. Eliaz, and C. N. Sukenik, "Thin film oxide barrier layers: protection of Kapton from space environment by liquid phase deposition of titanium oxide," ACS Applied Materials \& Interfaces, vol. 2, no. 7, pp. 1835-1843, 2010. 